\title{
BMJ Open How do patients from South Asian backgrounds experience life on haemodialysis in the UK? A multicentre qualitative study
}

\author{
Shivani Sharma, ${ }^{1}$ Madeline King, ${ }^{1}$ Roisin Mooney, ${ }_{1}$ Andrew Davenport, ${ }^{2}$ Clara Day, ${ }^{3}$ \\ Neill Duncan, ${ }^{4}$ Kirit Modi, ${ }^{5}$ Maria Da Silva-Gane, ${ }^{6}$ David Wellsted, ${ }^{7}$ Ken Farrington ${ }^{8}$
}

To cite: Sharma S, King M, Mooney R, et al. How do patients from South Asian backgrounds experience life on haemodialysis in the UK? A multicentre qualitative study. BMJ Open 2019;9:e024739. doi:10.1136/ bmjopen-2018-024739

- Prepublication history for this paper is available online. To view these files, please visit the journal online (http://dx.doi. org/10.1136/bmjopen-2018024739).

Received 25 June 2018 Revised 18 January 2019 Accepted 13 March 2019
Check for updates

(C) Author(s) (or their employer(s)) 2019. Re-use permitted under CC BY-NC. No commercial re-use. See rights and permissions. Published by BMJ.

For numbered affiliations see end of article.

Correspondence to

Dr Shivani Sharma;

s.3.sharma@herts.ac.uk

\section{ABSTRACT}

Objectives End-stage kidney disease disproportionately affects people of South Asian origin. This study aimed to uncover the lived experiences of this group of patients on centre-based haemodialysis (HD), the most prevalent dialysis modality.

Design The study utilised a qualitative focus group methodology. Seven focus groups were conducted across four NHS Trusts in the UK including three in Gujarati and two each in Punjabi and Urdu. This provided an inclusive opportunity for South Asian patients to contribute in their language of origin. A total of 24 patients participated. Focus groups were facilitated by bilingual project workers and data were forward translated and analysed using thematic analysis.

Results Four themes were identified. This included (1) 'treatment imposition', which comprised of the restrictive nature of $\mathrm{HD}$, the effects of treatment and the feeling of being trapped in an endless process. (2) The 'patientclinician relationship' centred around the impact of a perceived lack of staff time, and inadequacies in the quality of interactions. (3) 'Coping strategies' highlighted the role of cognitive reappraisal, living in the moment and family support networks in facilitating adjustment. (4) 'Pursuit of transplantation' included equating this form of treatment with restoring normality, alongside cultural factors limiting hopefulness for receiving an organ. Conclusions In general, the experiences of South Asian patients receiving HD were not unique to this ethnic group. We did find distinct issues in relation to interactions with healthcare professionals, views on access to transplantation and the importance of family support networks. The study provides useful insights which may help enhance culturally tailored renal care.

\section{INTRODUCTION}

Patients with end-stage kidney disease (ESKD) require some form of kidney function replacement in order to survive. In the UK, more than one person in every thousand receives such treatment, the most common forms of which are kidney transplantation and haemodialysis (HD). ${ }^{1}$ HD involves removal of toxins from the patient's blood by passage through

\section{Strengths and limitations of this study}

- The use of qualitative focus group methodology allowed for in-depth exploration of patient experiences, and has resulted in new knowledge on how members of ethnic minorities experience haemodialysis (HD) care.

- The opportunity for patients to engage in focus groups in their language of origin overcame barriers that may otherwise prevent participation in research.

- The bilingual project workers who facilitated focus groups were unrelated to patient renal care and so were able to more effectively encourage participation so that all individuals contributed to the discussions.

- The self-selecting nature of patient participants may have resulted in recruitment bias such that only those with strong views about HD participated.

a dialysis machine. This requires access to the patient's bloodstream through a surgically created fistula or a permanent intravenous line. Treatment needs to be conducted regularly, usually thrice weekly with each session lasting around 4 hours.

While HD is a lifesaving treatment, it is physically and psychologically demanding. Studies have demonstrated the high symptom burden associated with treatment including symptoms during dialysis, such as headaches, low blood pressure, fatigue (both generally and postdialysis in particular $)^{23}$ and sleep disturbances. ${ }^{45}$ Additionally, patients need to contend with dietary and fluid restrictions, ${ }^{6-8}$ high pill burden ${ }^{9} 10$ and often struggle to participate in life activities. ${ }^{11}$ The frequency of HD treatments is an added stressor. ${ }^{12} 13$

Although there is considerable literature exploring patient perspectives of life on HD, there has been little focus on ethnic minorities, relating in part to language and cultural barriers. ${ }^{14}$ This represents an important gap in knowledge, since a significant proportion 
(22.7\%) of UK service users identify themselves as having a Black and Asian Minority Ethnic (BAME) background, the largest group being those originating from South Asia $(11.8 \%) .^{1}$ South Asian refers here to people with origins in India, Pakistan, Bangladesh and Sri Lanka. Compared with their white-European counterparts, people of South Asian origin are at increased risk of developing ESKD. ${ }^{1516}$ The mechanisms for vulnerability are likely to be related to susceptibility to risk factors such as diabetes. ${ }^{17}$ South Asians are more likely to develop ESKD at a younger age ${ }^{18}$ and have a faster rate of symptom progression. ${ }^{19}$ They are also likely to wait longer for a renal transplant primarily due to reduced rates of organ donation among people of this ethnicity. ${ }^{20}$

Currently, little is known about how South Asian patients adjust to and cope with HD. The limited data available suggest perceptions of reduced quality of life when compared with white-Europeans, ${ }^{21}$ together with increased symptom burden both during and between HD sessions. ${ }^{2}$ There may also be problems with referral processes, particularly for those moving from diabetic to renal services. ${ }^{22}$ This lack of data has been recognised in the inaugural UK Renal Research Strategy, which states that efforts should be made to increase access to research for those from BAME groups. ${ }^{23}$

We sought to provide South Asian patients with a culturally tailored opportunity to share their thoughts, feelings and experiences of $\mathrm{HD}$, in relation to the processes involved in HD treatment and its impact on their lives. We utilised a qualitative focus group approach, since it offers an in-depth account of patient perspectives and so may generate important findings for both healthcare policy and clinical practice. ${ }^{24}$

\section{METHODS}

The research is reported according to the Consolidated Criteria for Reporting Qualitative Studies. ${ }^{25} \mathrm{~A}$ semistructured focus group topic guide was devised by the authors, a multiprofessional team with expertise in health psychology, nephrology, patient and public involvement, qualitative methods and psychological care. The topic guide (table 1) included seven items across three core areas: patient perspectives on HD and its impact on their life, thoughts and feelings in relation to health and support mechanisms. Probing questions were asked as appropriate to encourage patients to expand on their answers. Since research with South Asian patients is limited, the topic guide was kept purposefully broad in order to encourage patients to discuss elements of their experience that are most meaningful to them as opposed to being guided by existing literature. First developed in English, the topic guide was forward translated into Gujarati, Punjabi and Urdu by a team of bilingual project workers with a background of working in healthcare contexts and with patients of South Asian origin. Four project workers were employed working with patients from ethnic minorities as peer educators, in community liaison and nursing. Two
Table 1 Focus group topic guide

\begin{tabular}{|c|c|}
\hline Topic guide area & Questions \\
\hline $\begin{array}{l}\text { Impact of } \\
\text { haemodialysis }\end{array}$ & $\begin{array}{l}\text { How has your life changed since } \\
\text { starting dialysis? } \\
\text { Which aspects of your life have been } \\
\text { most affected? } \\
\text { Are you happy with the treatment that } \\
\text { you receive? }\end{array}$ \\
\hline $\begin{array}{l}\text { Thoughts and } \\
\text { feelings about health }\end{array}$ & $\begin{array}{l}\text { How do you feel about your situation? } \\
\text { Do you have any concerns about your } \\
\text { future health? } \\
\text { What bothers you most about your } \\
\text { health at present? }\end{array}$ \\
\hline Support & $\begin{array}{l}\text { What has helped you to cope with } \\
\text { the lifestyle changes associated with } \\
\text { dialysis? }\end{array}$ \\
\hline
\end{tabular}

others had experience in supporting healthcare research with members of BAME groups. The majority of project workers $(83 \%)$ were female. We recruited two project workers in each language who independently translated the topic guide and met to reconcile any disagreements. The project workers also attended three training days focused on the conceptual background and aims of the study, research processes, translation processes and transcription. Training was delivered by a multidisciplinary team.

\section{Setting}

The research was based across four UK NHS Renal Units with high proportions of patients from South Asian backgrounds $(18 \%-30 \%) .{ }^{1}$ Patients were given the option to attend focus groups on dialysis or non-dialysis days. On HD days, this could be before or after treatment and the focus groups were then scheduled based on the preference of the majority.

\section{Participants and recruitment}

An initial audit was carried out by each NHS Trust to estimate the proportions of patients who identified themselves with different South Asian subgroups. This identified three main languages: Gujarati, Punjabi and Urdu. This captured those with origins in India and Pakistan including Gujarati speaking Hindus and Punjabi speaking Sikhs from India, and Urdu speaking Muslims from India and Pakistan. Focus groups were conducted in the language of origin so as to provide patients equal opportunities to contribute. Eligible patients were identified by their consultant nephrologist. Inclusion criteria were age over 18 years, receiving HD for at least 6 months, and verbally fluent in one of the target languages. Patients who had received treatment for mental health problems within the last year were excluded. Eligible patients were provided with a written information sheet by a member of the renal care team, usually someone with the appropriate language skills. Those interested in the study were asked to consent to their information being passed onto 
the research team. Each patient then received a follow-up telephone call from a bilingual project worker who provided further information and details of the focus groups. At the focus groups, patients were reminded about the particulars of the research and informed consent was taken by a bilingual project worker supported by the study co-ordinator (RM). The focus groups began by patients introducing themselves and then moved through areas of the topic guide. At the end of the focus group, patients were debriefed and thanked.

\section{Data analysis}

All focus groups were audio recorded with consent from patients and transcribed verbatim by the associated project worker. The project worker then forward translated the transcripts into English. At this stage, a second bilingual project worker independently reviewed the transcript to provide assurance of the quality of translation, with a particular focus on retaining meaning. Data were analysed by SS and MK in NVivo qualitative software V.10 and using thematic analysis as described by Braun and Clarke. ${ }^{26}$ Transcripts were first read and reread to form initial impressions of the data. We then progressed to code interesting aspects of the data and started to group similar ideas and concepts together. On this basis, a codebook was agreed on and analysis progressed to revise the codes and to identify overarching themes that subsumed them. Verbatim text from the focus groups was incorporated to further elucidate the themes. It is important to mention that recognising the lack of robust guidelines on attaining data or theoretical saturation in qualitative studies, ${ }^{27}$ we defined saturation in this research as the point at which patient participants were not 'telling us anything new' and our codebook had been stabilised. This was achieved by analysis of the fourth focus group and so we are confident that at the level of the higher order concepts we sought to explore, our themes accurately capture the range of experiences that patient had to share. Ongoing discussion between SS and MK, and SS and the project workers throughout data analysis also helped to ensure that the themes accurately represented what patients conveyed within the focus groups. While deploying two coders increased resource demands, the added benefits were the different perspectives that SS and MK brought to the task, given their differing research experiences, together with the opportunity it presented to discuss the coding in-depth, to resolve disagreements and to refine the codebook and themes. RM also coded $20 \%$ of the transcripts. Cohen's kappa was used to calculate inter-rater reliability. This indicated substantial agreement ${ }^{27}$ with a $\mathrm{k}$ value of 0.80 .

\section{Patient and public involvement}

Patient involvement was essential to identifying the need for the research, the development of the recruitment strategy and the interpretation of findings. KM has experience as both a HD patient and kidney transplant recipient and is also an active member of a number of patient advocacy groups. This breadth of experience allowed KM to provide feedback throughout the development of the research proposal, and at key junctures of the research process including data interpretation and dissemination of findings.

\section{RESULTS}

Seven focus groups were conducted. This included two in each Urdu and Punjabi and three in Gujarati according to the language needs of patients based at the included NHS Trusts. Focus groups lasted from $45 \mathrm{~min}$ to 1.5 hours, and included three to four patients. Twenty-four patients participated ( $\mathrm{M}$ age $=57.4 ; \mathrm{SD}=8.9$ ) including 14 males and 10 females. Four themes emerged from the data.

\section{Theme 1: treatment imposition}

Patients were forthcoming with examples of how HD had imposed on their lives. Notably, their experiences related to the 'restrictive' nature of HD, 'treatment effects' and a sense of being stuck in an 'endless process'. There were multiple attributes linked to perceiving HD to be restrictive, stemming mainly from treatment frequency and the impact this had on engagement with a wide range of activities and restricting patient autonomy over life participation. Such feelings are highlighted in the following extract:

I can't go on holidays. If I want to go out far, then I have to think twice about it as have to be back for dialysis the next day. That is a problem (Gujarati focus group 2, patient 2, male).

A further example of patients feeling as though dialysis restricted life participation includes conflict between treatment attendance and cultural needs such as observing prayers.

Recently with my having to attend cultural prayers and the last 3 days I have been running around and luckily yesterday afternoon I got dialysis and I was able to go to the prayer but this is my example but when this happens and a person gets pulled by cultural needs it debilitates a person (Gujarati focus group 1 , patient 2, female).

Treatment effects were also wide ranging. A minority reported side effects of medication such as altered taste.

I have a problem with eating as too much medication has made the tongue feel bitter (Gujarati focus group 2 , patient 4 , female).

Other treatment effects described as problematic were predominantly associated with HD (during or in-between sessions) such as feeling weak, experiencing low blood pressure and headaches.

I feel like going out but don't feel well enough. I either have a headache or my legs ache, I feel weak. I do want to go out for a short walk but the body doesn't 
allow you to do what you want (Gujarati focus group 2 , patient 3 , female).

When you come off dialysis, your whole body aches. And you don't have the strength. It takes probably all evening to get back to normal, or the next day (Urdu focus group 2, patient 3, male).

A final imposition of treatment was the feeling that patients are stuck in and endless process where they have no choice over their circumstances, which led to despondency.

Sometimes we [referring to the whole focus group] don't feel like coming, but we don't have a choice, we have to (Urdu focus group 1, patient 4, female).

Yes, keep going, you have no choice (Punjabi focus group 1, patient 1, male).

\section{Theme 2: patient-clinician relationship}

As part of discussing life on dialysis, the patient-clinician relationship featured as a central factor that impacted overall perceptions of healthcare. This included some patients feeling dissatisfaction about a perceived 'lack of time' available from nephrologists:

The doctors don't have time. We try to meet with them as regularly as possible (Punjabi focus group 2, patient 3 , female).

Additionally, it was clear that patients were divided in their experiences of healthcare professionals due to perceived inadequacy in quality of interactions. The following example illustrates this:

The doctors they just give you the medication, use this. They don't explain. Take this medication, what is going in your body they don't explain about it. They don't tell you what is going wrong or what you have to do. Just this is your prescription, take the medication. Their responsibility is finished (Urdu focus group 1, patient 5 , female).

Perceived difficulties in developing positive patientclinician interactions were in part enhanced by language barriers that prevented patients from directly communicating with their healthcare professional, rendering the family support network as crucial.

I do not understand what he [referring to the nephrologist] says. When there is a meeting, my daughter writes down the points and gives me (Gujarati focus group 2, patient 2, male).

Some [referring to others that the patient interacted with] don't know at all...like mostly the elderly need to take someone in...if it's an English doctor, they'll need to take someone in to understand (Punjabi focus group 1, patient 2, male).

\section{Theme 3: coping strategies}

Despite noting a range of negative impositions on life brought about by HD and its associated complexities, patients recognised a need to maintain a positive outlook. This was driven by the 'cognitive re-appraisal' that HD was at least a lifeline and that it was more psychologically helpful to 'live in the moment'. For example, patients described HD as extending their life and giving them a second chance:

I think that I have received a bonus life. This is my bonus life. It is hard. But I have been given another chance in this world. My view is that whatever time holds you should remain happy. Positive thinking. We do think on the other side too, like when we go on the machine, we have a lot of tension in our mind, but we should still think this is still good for us (Urdu focus group 1 , patient 1 , female).

Patients also felt that it was more constructive to live in the moment rather than dwell on negativity:

You need to take each day as it comes and live mindfully (Gujarati focus group 1, patient 3, male).

Additionally, patients perceived receiving support from the 'family network' as extremely important in helping them to contend with HD. Family offered two types of support. First, 'practical support' in multiple domains related to treatment itself such as communicating with professionals on their behalf for those who had no or limited English language skills (as described in Theme 3: coping strategies section). Second, family offered emotional comfort in facing patient circumstances with the majority viewing them as the first and often only source of support:

There are low moods, apart from your children who are close to you, only they understand you (Urdu focus group 1, patient 4 , female).

Having a good family unit is very important, very important I think. You know your close family. They can help you, they can help cheer you up, they look after you (Punjabi focus group 1, patient 2, male).

\section{Theme 4: pursuit of transplantation}

Given the challenges associated with HD, the majority of patients described a kidney transplant as a route to improving their quality of life. Transplantation was equated to 'normality' as described in the following extract:

I have been coming here since 8 years, I don't get a response as to whether I will get a kidney or not. I think if I get a transplant, then the next 8-10 years of my life would go in peace (Gujarati focus group 2, patient 2, male).

However, there was a 'loss of hopefulness' for transplantation relating to an awareness of a lack of suitable or willing donors, especially those from ethnic minorities. The following quotes demonstrate the perception that live donation may be less likely among the South Asian 
community owing to a lack of knowledge and awareness of the process.

That's the thing. It's because Indian's don't have enough information. Like they haven't said that $\mathrm{Mr}$ Singh gave his kidney away to his sister and that person is still well. Whereas English people, they have the information about so and so gave this. They can see people who have done it. They can feel satisfied that this person has given it away and that they are still OK and that I am also OK to do it. And we [referring to own community] don't have that system, because no-one does it that much (Punjabi focus group 1 , patient 1 , male).

Furthermore, patients reported that when discussing transplantation with potential live donors they were met by disbelief that this was a possibility.

I've been waiting for years and I've had enough so if anything can be done about a transplant, that would be appreciated...I've been told that a person can survive on one kidney, but when I tell others they don't believe me; I think they are scared (Punjabi focus group 2, patient 2, male).

\section{DISCUSSION}

Using focus group methodology, we highlight how patients from South Asian backgrounds experience life on HD. The findings concur with existing research suggesting that there are consistent aspects of treatment via $H D$, which patients find difficult to contend with and consequently employ a number of strategies to help them cope. ${ }^{12} 2829$ The major contribution of our study is identifying that South Asian patients often report difficulties in developing positive patient-clinician relationships, which may lead to perceived health disparities, alongside the loss of hope for escaping the HD treatment regimen due to the availability of donor kidneys.

Our patients echoed the treatment impositions of HD such as the frequency of sessions restricting engagement with day-to-day activities and limiting general autonomy in life. Additionally, patients were forthcoming in expressing the added treatment effects that are problematic both during and between HD sessions. Since HD is a lifesaving treatment, the impact on symptom burden may be overlooked, ${ }^{2}$ but it is important to note the range of factors that patients may need support with when adjusting to a new way of living. For example, in their qualitative study concerning the experience of fatigue in HD patients, Horigan et $a l^{30}$ reported that fatigue has consequences for activities such as socialising, spending time with loved ones and participating in other life activities. Such added burden appears to amplify the relentless nature of HD and contributes to a sense that patients are enduring their circumstances and are stuck, having no choice but to continue in order to survive.
Despite being forthcoming about the negative aspects of HD, the patients in this study recognised the importance of maintaining a positive outlook about their circumstances, acknowledging that HD has provided them with a lifeline. The sense of a renewed or extended life facilitated by cognitive reappraisal of patient circumstances concurs with the views expressed by HD patients in other studies. ${ }^{12829}$ Additionally, part of maintaining a positive outlook involved living in the moment and taking each day as it comes. Such an approach has also been unearthed in carers of patients with ESKD as a mechanism to cope with uncertainty. ${ }^{31}$ The development of a positive outlook may be an adaptive process to the demands of HD and an important constructive coping strategy.

Support from the family was also an important coping resource. Family offered both practical support and emotional comfort. There is a wealth of research delineating the positive impact of perceived social support in the context of HD. For example, a study of Iranian HD patients found that perceived social support was associated with quality of life. ${ }^{32}$ Social support also has a positive impact on patient adherence and mood on dialysis. ${ }^{33}{ }^{34}$ Hence for patients from BAME backgrounds, it is important to focus on understanding support networks to facilitate achievement of acceptable quality of life and health outcomes. This is particularly relevant where there are language barriers and family support is required facilitate engagement with treatment.

Although we did not specifically enquire about the patient-clinician relationship, this emerged as an important theme in our data. Many patients reported issues in the amount of time they perceived receiving from nephrologists and mixed experiences of the quality of patient-clinician interactions. It is not uncommon for members of ethnic minorities to report negative experiences of interactions with physicians. ${ }^{35}{ }^{36}$ However, difficulties in relationships with healthcare professionals are not limited to those from ethnic minorities. Longitudinal participatory action research conducted with English speaking HD patients in Canada found that perceived failure of healthcare professionals to interact with the patient as a whole person led to a lack of trust. ${ }^{37}$ What may be unique to patients from ethnic minorities are the added language barriers that may further limit the quality of interactions. Strategies to improve rapport need to include the broader family network since this is a major source of patient support.

A notable finding relates to kidney transplantation being perceived as a route to optimising quality of life. Indeed, kidney transplantation is the most desirable and economic form of renal replacement therapy (RRT), offering the best outcomes. ${ }^{38}$ However, it is true that due to low rates of organ donation among those from BAME backgrounds, these patients can expect to wait on average up to a year longer for a kidney transplant compared with their white counterparts. ${ }^{20}$ Our patients believed that there is a lack of knowledge and awareness surrounding organ donation in their communities as compared with 
those from white-European backgrounds and particularly regarding live donation as they encountered difficulty in discussing donation with friends and family. Such feelings may be a further challenge to adaptation to HD. ${ }^{39}$

There are multiple reasons for lower rates of organ donation among BAME groups. Morgan et $a l^{20}$ summarised them into five main themes: a lack of knowledge about organ donation and how to register to become a donor, faith and cultural beliefs, bodily concerns, family influence and trust in the healthcare system. Morgan $e t a t^{20}$ suggest that tailored community-based educational interventions may be more beneficial for improving rates of donation among BAME groups over mass media campaigns. Although rates of live donation are equivalent to those of other ethnic groups, ${ }^{40}$ more efforts appear to be required to both raise awareness of the success of live donation and to encourage deceased donation. It may also be important to empower patients so that they feel able to initiate discussions around live donation, although research suggests that it may be useful to separate the patient from the advocate. ${ }^{41}$ Initiatives such as community-based peer educators in BAME communities may help address the spectrum of issues related to kidney disease. ${ }^{42}$

\section{Strengths and limitations}

Patients from BAME backgrounds are under-represented in renal research due to language and cultural barriers. ${ }^{14}$ By providing an opportunity to contribute to focus groups in their language of origin that were facilitated by project workers unrelated to renal care, the study has helped capture the treatment experiences of a major group of HD patients in the UK. Recruitment across four NHS Renal Units also helped ensure diverse perspectives from those receiving care at different centres. There are some limitations: (1) the self-selecting nature of the study participants may have introduced bias into the study and it is plausible that only patients with strong views about HD participated. This may explain why our findings share a high level of similarity with other qualitative studies in the area of HD. (2) The number of participants included in each focus group was relatively small and the reasons for non-participation largely unknown.

\section{CONCLUSIONS}

This study contributes new knowledge about how HD is experienced by patients from South Asian backgrounds in a UK renal care setting. The findings support the need to help all patients in adapting to the HD treatment regimen including the usefulness of developing positive coping strategies. For patients where language barriers impede the formation of the patient-clinician relationships, it is essential to involve the wider support network effectively in healthcare discussions and in a way that empowers patients in managing their illness. Campaigns aimed at addressing the shortage of donor organs should be encouraged to improve hopefulness for normality and ultimately rates of access to kidney transplantation for those from BAME backgrounds.

\section{Author affiliations}

${ }^{1}$ Psychology and Sports Sciences, University of Hertfordshire, Hatfield, UK ${ }^{2}$ Edgware Kidney Care Unit, Royal Free NHS Foundation Trust, London, UK ${ }^{3}$ Renal Unit, Queen Elizabeth Hospital, University Hospitals Birmingham NHS Foundation Trust, Birmingham, UK

${ }^{4}$ Northwick Park Hospital Dialysis Centre, Imperial College Healthcare NHS Trust, London, UK

${ }^{5}$ National Kidney Federation, Nottingham, UK

${ }^{6}$ Renal Medicine, Lister Hospital, Stevenage, UK

${ }^{7}$ Centre for Health Services and Clinical Research, University of Hertfordshire, Hatfield, UK

${ }^{8}$ Renal Unit, Lister Hospital, Stevenage, UK

Acknowledgements We would like to thank all patients who participated in the research for contributing their experiences, thoughts and feelings. Additionally, we would like to acknowledge the bilingual project workers for their support throughout the research (Jay Chandarana, Usha Shah, Indra Sharma, Riffat Mahmood, Sultan Mahmood and Indira Thakrar).

Contributors The research was conceived by SS, DW, MDS-G and KF. AD, CD, $\mathrm{ND}$ and $\mathrm{KM}$ contributed to the design of the study, with KM providing a patient and public involvement perspective throughout. AD, CD, ND and KF also acted as principal investigators in their local NHS Trusts. SS, MK and RM performed the data analysis and interpretation. SS wrote the manuscript and all coauthors contributed to reviewing drafts and approved the submitted version.

Funding This work was supported by the British Renal Society and British Kidney Patient's Association.

Competing interests None declared.

Patient consent for publication Not required.

Ethics approval The research was approved by the London Brent Health Research Authority (reference number 13/L0/1078).

Provenance and peer review Not commissioned; externally peer reviewed.

Data sharing statement No additional data are available.

Open access This is an open access article distributed in accordance with the Creative Commons Attribution Non Commercial (CC BY-NC 4.0) license, which permits others to distribute, remix, adapt, build upon this work non-commercially, and license their derivative works on different terms, provided the original work is properly cited, appropriate credit is given, any changes made indicated, and the use is non-commercial. See: http://creativecommons.org/licenses/by-nc/4.0/.

\section{REFERENCES}

1. MacNeill SJ, Casula A, Shaw C, et al. UK Renal Registry 18th Annual Report: Chapter 2 UK Renal Replacement Therapy Prevalence in 2014: National and Centre-specific Analyses. Nephron 2016;132(Suppl 1):41-68.

2. Caplin B, Kumar S, Davenport A. Patients' perspective of haemodialysis-associated symptoms. Nephrol Dial Transplant 2011;26:2656-63.

3. Horigan AE. Fatigue in hemodialysis patients: a review of current knowledge. J Pain Symptom Manage 2012;44:715-24.

4. Parker KP. Sleep disturbances in dialysis patients. Sleep Med Rev 2003;7:131-43.

5. Elias RM, Chan CT, Bradley TD. Altered sleep structure in patients with end-stage renal disease. Sleep Med 2016;20:67-71.

6. Palmer SC, Hanson CS, Craig JC, et al. Dietary and fluid restrictions in CKD: a thematic synthesis of patient views from qualitative studies. Am J Kidney Dis 2015;65:559-73.

7. Yu J, Ng HJ, Nandakumar M, et al. The management of food cravings and thirst in hemodialysis patients: A qualitative study. $J$ Health Psychol 2016;21:217-27.

8. Kalantar-Zadeh K, Tortorici AR, Chen JL, et al. Dietary restrictions in dialysis patients: is there anything left to eat? Semin Dial 2015;28:159-68.

9. Chiu YW, Teitelbaum I, Misra M, et al. Pill burden, adherence, hyperphosphatemia, and quality of life in maintenance dialysis patients. Clin J Am Soc Nephrol 2009;4:1089-96. 
10. Browne T, Merighi JR. Barriers to adult hemodialysis patients' selfmanagement of oral medications. Am J Kidney Dis 2010;56:547-57.

11. Purnell TS, Auguste P, Crews DC, et al. Comparison of life participation activities among adults treated by hemodialysis, peritoneal dialysis, and kidney transplantation: a systematic review. Am J Kidney Dis 2013;62:953-73.

12. Hagren B, Pettersen IM, Severinsson E, et al. The haemodialysis machine as a lifeline: experiences of suffering from end-stage renal disease. J Adv Nurs 2001;34:196-202.

13. Monaro S, Stewart G, Gullick J. A 'lost life': coming to terms with haemodialysis. J Clin Nurs 2014;23(21-22):3262-73.

14. Sharma S, Bhui K, Chilcot J, et al. Identifying depression in South asian patients with end-stage renal disease: considerations for practice. Nephron Extra 2011;1:262-71.

15. Roderick PJ, Raleigh VS, Hallam L, et al. The need and demand for renal replacement therapy in ethnic minorities in England. $J$ Epidemiol Community Health 1996;50:334-9.

16. Trehan A, Winterbottom J, Lane B, et al. End-stage renal disease in Indo-Asians in the North-West of England. QJM 2003;96:499-504.

17. Dabla PK. Renal function in diabetic nephropathy. World J Diabetes 2010;1:48-56.

18. Roderick P, Byrne C, Casula A, et al. Survival of patients from South Asian and Black populations starting renal replacement therapy in England and Wales. Nephrol Dial Transplant 2009;24:3774-82.

19. Barbour SJ, Er L, Djurdjev O, et al. Differences in progression of CKD and mortality amongst Caucasian, Oriental Asian and South Asian CKD patients. Nephrol Dial Transplant 2010;25:3663-72.

20. Morgan M, Sims J, Jain N, et al. Who waits longest for a kidney?: Inequalities in access to kidney transplantation among Black and Asian Minority Ethnic (BAME) groups in the UK. British Journal of Renal Medicine 2015;20:4-7.

21. Bakewell $A B$, Higgins RM, Edmunds ME. Does ethnicity influence perceived quality of life of patients on dialysis and following renal transplant? Nephrol Dial Transplant 2001;16:1395-401.

22. Wilkinson E, Randhawa G, Feehally J, et al. A multi-centre qualitative study exploring the experiences of UK South Asian and white diabetic patients referred for renal care. BMC Nephrol 2012;13:1-7.

23. Karet Frankl F, Coward R, Gallagher H, et al. UK Renal Research Strategy, 2016

24. Tong A, Winkelmayer WC, Craig JC. Qualitative research in CKD: an overview of methods and applications. Am J Kidney Dis 2014:64:338-46.

25. Tong A, Sainsbury P, Craig J. Consolidated criteria for reporting qualitative research (COREQ): a 32-item checklist for interviews and focus groups. Int J Qual Health Care 2007;19:349-57.

26. Braun V, Clarke V. Using thematic analysis in psychology. Qual Res Psychol 2006;3:77-101.
27. Landis JR, Koch GG. The measurement of observer agreement for categorical data. Biometrics 1977;33:159-74.

28. Hasani P, Otaghi M, Zagheri TM, et al. The Meaning of Transition to Hemodialysis: qualitative study. IJCNN 2013;6:73-80.

29. Mitchell A, Farrand P, James $H$, et al. Patients' experience of transition onto haemodialysis: a qualitative study. J Ren Care 2009;35:99-107.

30. Horigan AE, Schneider SM, Docherty S, et al. The Experience and Self-Management of Fatigue in Hemodialysis Patients. Nephrology nursing journal: journal of the American Nephrology Nurses' Association 2013;40:113-23.

31. Pelletier-Hibbert M, Sohi P. Sources of uncertainty and coping strategies used by family members of individuals living with end stage renal disease. Nephrol Nurs J 2001;28:411.

32. Rambod M, Rafii F. Perceived social support and quality of life in Iranian hemodialysis patients. J Nurs Scholarsh 2010;42:242-9.

33. DiMatteo MR. Social support and patient adherence to medical treatment: a meta-analysis. Health Psychol 2004;23:207-18.

34. Patel SS, Peterson RA, Kimmel PL. PSychosocial factors in patients with chronic kidney disease: The impact of social support on endstage renal disease. Semin Dial 2005;18:98-102.

35. Cooper-Patrick L, Gallo JJ, Gonzales JJ, et al. Race, gender, and partnership in the patient-physician relationship. JAMA 1999;282:583-9.

36. Saha S, Arbelaez JJ, Cooper LA. Patient-physician relationships and racial disparities in the quality of health care. Am J Public Health 2003:93:1713-9.

37. Allen $\mathrm{D}$, Wainwright $\mathrm{M}$, Hutchinson $\mathrm{T}$. 'Non-compliance' as illness management: Hemodialysis patients' descriptions of adversarial patient-clinician interactions. Soc Sci Med 2011;73:129-34.

38. Liyanage T, Ninomiya $T$, Jha V, et al. Worldwide access to treatment for end-stage kidney disease: a systematic review. Lancet 2015;385:1975-82

39. Burns T, Fernandez R, Stephens M. The experiences of adults who are on dialysis and waiting for a renal transplant from a deceased donor: a systematic review. JBI Database System Rev Implement Rep 2015;13:169-211. Electronic:169-211.

40. Perera S, Mamode N. South Asian patients awaiting organ transplantation in the UK. Nephrol Dial Transplant 2011;26:1380-4.

41. Garonzik-Wang JM, Berger JC, Ros RL, et al. Live donor champion: finding live kidney donors by separating the advocate from the patient. Transplantation 2012;93:1147.

42. Jain N. Increasing black, asian and minority ethnic (bame) patient \& community awareness--using the peer educator model. J Ren Care 2014;40(S1):36-40. 